Available online at: http://e-journal.upstegal.ac.id/index.php/jip

Submission: 31-07-2017; Revision: 26-02-2018; Publish: 30-05-2018

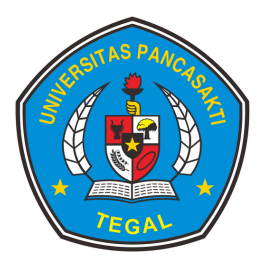

DOI: http://dx.doi.org/10.24905/jip.v3i1.868

\title{
Analisis Dampak Pemekaran Daerah Terhadap Kinerja dan Pemerataan Ekonomi di Kabupaten Lombok Utara
}

\author{
Raden Hady Santika 1) *, Budi Santoso 2), Hadi Mahmudi3) \\ 1,2,3 Program Magister Ilmu Ekonomi, Universitas Mataram, Nusa Tenggara Barat, Indonesia. \\ * Korespondensi Penulis. E-mail: hady80an@yahoo.com, Telp: +6281917298122
}

\begin{abstract}
Abstrak
Pemekaran daerah merupakan upaya untuk mewujudkan efektivitas penyelenggaraan pemerintahan, pelaksanaan pembangunan dan pembinaan kemasyarakatan serta untuk lebih mempercepat terwujudnya pemerataan kesejahteraan masyarakat. Tujuan penelitian ini adalah menganalisis dampak pemekaran daerah terhadap kinerja ekonomi dan pelayanan publik serta tingkat pemerataan ekonomi di Kabupaten Lombok Utara. Penelitian ini menggunakan metode kuantitatif, lokasi penelitian ini di Kabupaten Lombok Utara Provinsi Nusa Tenggara Barat. Teknik pengumpulan data menggunakan studi literatur, dokumentasi dan wawancara. Berdasarkan hasil penelitian dapat disimpulkan bahwa kinerja ekonomi, kinerja pelayanan publik dan pemerataan ekonomi setelah pemekaran daerah mengalami peningkatan. Pemekaran daerah di Lombok Utara memberikan dampak positif bagi pembangunan daerah dan memperoleh penghargaan di berbagai bidang baik tingkat Provinsi, Nasional dan Internasional.
\end{abstract}

Kata kunci: Kinerja, Otonomi Daerah, Pemerataan Ekonomi

\section{The Impact of Regional Expansion to Performance and Equity of Economic Decision in North Lombok District}

\begin{abstract}
Expansion of regions is an effort to realize the effectiveness of governance, development and community development and to accelerate the realization of equitable distribution of society. The purpose of this study is to analyze the impact of regional expansion on economic performance and public service and the level of economic equity in North Lombok Regency. This research uses quantitative method, the location of this research is in North Lombok Regency West Nusa Tenggara Province. Technique of collecting data using literature study, documentation and interview. Based on the results of the study can be concluded that economic performance, performance of public services and economic equity after the expansion of the region has increased. The division of the region in North Lombok has had a positive impact on regional development and earned awards in various fields at provincial, national and international levels.
\end{abstract}

Keywords: Performance, Regional Expansion, Equity of Economic. 


\section{Jurnal Ilmu Pemerintahan: Kajian Ilmu Pemerintahan dan Politik Daerah, \\ Vol 3 (1), April 2018 - 16 \\ Raden Hady Santika, Budi Santoso, Hadi Mahmudi}

\section{PENDAHULUAN}

Syarat utama bagi pembangunan ekonomi ialah bahwa proses pertumbuhannya harus bertumpu pada kemampuan perekonomian di dalam negeri. Hasrat untuk meperbaiki nasib dan prakarsa untuk menciptakan kemajuan material harus muncul dari warga negara itu sendiri. Kekuatan luar seyogyanya merangsang dan membantu kekuatan nasional. Pembangunan tidak mungkin dilakukan jika ia tidak sesuai dengan keinginan rakyat, sehingga agar proses pertumbuhan ekonomi dapat berumur panjang dan bersifat kumulatif maka proses pembangunan tersebut harus benar-benar berakar dari kekautan dalam negeri (Jhingan, 1985).

Perkembangan wilayah biasanya merupakan wujud dari keinginan masyarakat di suatu daerah untuk tumbuh dan berkembang dari segi ekonomi, politik, sosial, budaya dan keamanan, dalam dimensi geografis. Tingkat perkembangan wilayah dapat dilihat dari rasio luas wilayah terbangun (built-up area) terhadap total luas wilayah. Semakin besar rasionya, maka semakin tinggi tingkat perkembangan wilayahnya. Semakin luas built-up areanya dapat diartikan semakin tinggi aktivitas ekonomi masyarakatnya.Kondisi tersebut dapat dilihat dari semakin rapatnya jaringan jalan, semakin meluasnya wilayah perkantoran dan perdagangan, semakin menyebarnya wilayah pemukiman dengan kepadatan penduduk yang tinggi dan tingginya peluang kerja (D Harmantyo, 2011)

Pelaksanaan otonomi daerah walaupun masih banyak menimbulkan persoalan, akan tetapi banyak segi positif yang dapat terus dipacu dan dikembangkan agar dapat menumbuhkan iklim kondusif dengan tujuan supaya bisa memperkuat daerah, khususnya desa sebagai pondasi penguatan ekonomi guna mencapai kesejahteraan (welfare state) sesuai dengan amanat konstitusi (Hilman, 2017). Kajian yang telah dilakukan menunjukkan bahwa beberapa daerah otonom belum mampu mengejar ketertinggalannya dari daerah lain diantaranya kesenjangan ekonomi antar wilayah semakin melebar.

Menurut (UNDP \& 2008, n.d.) menunjukkan bahwa selama 5 tahun mekar, Daerah Otonom Baru (DOB) belum mampu mengejar ketertinggalannya dari daerah induk. Sebagian besar DOB mengalami laju pertumbuhan yang lebih pesat dibandingkan daerah induk dan ratarata nasional namun belum menunjukkan perkembangan dilihat dari penyediaan pelayanan publik dan kondisi sosial ekonomi masyarakat di daerah otonom baru (Djoko Harmantyo, 2007).

Undang-undang Nomor 23 Tahun 2014 tentang Pemerintahan Daerah membawa banyak perubahan dalam penyelenggaraan pemerintahan. Salah satunya adalah pembagian urusan pemerintahan daerah. Kewenangan pemerintahan daerah meliputi hal-hal sebagai berikut: 1). Pemerintah daerah menyelenggarakan urusan pemerintahan menurut asas otonomi dan tugas pembantuan dengan prinsip otonomi seluas-luasnya sesuai dalam sistem Negara Kesatuan Republik Indonesia. 2). Pemerintah daerah melaksanakan urusan pemerintahan konkuren yang diserahkan oleh pemerintah pusat menjadi dasar pelaksanaan otonomi daerah dengan berdasar atas asas tugas pembantuan. 3). Pemerintahan daerah dalam melaksanakan 


\section{Jurnal Ilmu Pemerintahan: Kajian Ilmu Pemerintahan dan Politik Daerah, \\ Vol 3 (1), April 2018 - 17 \\ Raden Hady Santika, Budi Santoso, Hadi Mahmudi}

urusan pemerintahan umum yang menjadi kewenangan presiden dan pelaksanaannya dilimpahkan kepada gubernur dan bupati/wali kota, dibiayai oleh APBN.

Pemekaran wilayah atau tepatnya membagi suatu daerah otonom menjadi beberapa daerah, bertujuan untuk mendekatkan dan mengoptimalkan pelayanan pemerintah kepada masyarakat, mempercepat pertumbuhan pembangunan guna meningkatkan kesejahteraan masyarakat di daerah tersebut. Partisipasi masyarakat akan meningkat karena akses yang lebih terbuka serta pengawasan yang lebih efektif karena wilayah pengawasan relatif lebih sempit (Sudiar, 2017) .

Dimensi utama yang menjelaskan efektif tidaknya penataan (pemekaran) daerah adalah pengawasan, komunikasi, dan koordinasi yang kesemuanya turut menentukan terhadap tingkat pelayanan masyarakat. Semakin jauh penduduk dari pusat pemerintahan, semakin kecil memperoleh sentuhan pelayanan. Permintaan terhadap pelayanan semakin meningkat menuntut pusat-pusat pemerintahan memperluas daerah layanannya. Akan tetapi pusat-pusat pelayanan memiliki keterbatasan (radius) jangkauan, sehingga diperlukan pusatpusat pelayanan lain yang dapat memenuhi kebutuhan pelayanan masyarakat. Dengan demikian dengan adanya penataan (pemekaran) daerah berarti menambah pusat-pusat pemerintahan sehingga pelayanan dapat menjangkau wilayahwilayah pemukiman yang sebelumnya terpencil dan pelayanan pemerintah dapat tersentuh secara merata keseluruh masyarakat yang pada akhirnya akan meningkatkan kesejahteraan masyarakat (Simangunsong \& Simangunsong, 2016).
August Losch dalam bukunya yang berjudul The conomics of Location yang terbit tahun 1954 yang kemudian disebut teori Pasar Losch (market area) menjelaskan bahwa lokasi penjual sangat berpengaruh terhadap jumlah konsumen yang dapat digarapnya. Makin jauh dari penjual, konsumen makin enggan membeli karena biaya transportasi untuk untuk mendatangi tempat penjual semakin mahal. Produsen harus memilih lokasi yang menghasilkan penjualan terbesar yang identic dengan penerimaan terbesar. Losch cenderung menyarankan agar lokasi produksi berada di pasar atau di dekat pasar (Rustiadi, Saefulhakim, \& Panuju, 2009).

Sementara itu (Zainudin, 2016) mengungkapkan alasan dilakukannya pemekaran daerah adalah: Preference for Homogeneity (kesamaan kelompok) atau historical etnic memungkinkan ikatan sosial dalam satu etnik yang sama perlu diwujudkan dalam satu daerah yang sama pula. Fiscal Spoil (insentif fiskal untuk memekarkan diri, dapat dari DAU/DAK), adanya jaminan dana transfer, khususnya Dana Alokasi Umum, dari pemerintah pusat ke pemerintah daerah menghasilkan keyakinan bahwa daerah tersebut akan dibiayai. Beaurocratic and Political Rent Seeking (alasan politik, dan untuk mencari jabatan penting/mobilitas vertikal). Administrative Dispersion, mengatasi rentang kendali pemerintahan. Alasan ini semakin kuat mengingat daerah-daerah pemekaran merupakan daerah yang cukup luas sementara pusat pemerintahan dan pelayanan masyarakat sulit dijangkau.

Sejalan dengan teori lokasi/market area, pelayanan kepada masyarakat oleh pemerintah akan berjalan lebih efektif dan efisien apabila lokasi masyarakat 


\section{Jurnal Ilmu Pemerintahan: Kajian Ilmu Pemerintahan dan Politik Daerah, \\ Vol 3 (1), April 2018 - 18 \\ Raden Hady Santika, Budi Santoso, Hadi Mahmudi}

berdekatan dengan pusat pemerintahan. Apabila pusat pemerintahan berada jauh dengan masyarakat maka dapat berdampak pada tidak maksimalnya aktivitas-aktivitas pemerintah dalam mensejahterakan masyarakatnya. Disamping itu biaya yang dikeluarkan juga akan lebih tinggi sehingga akan banyak potensi-potensi yang ada dalam amsyarakat tidak dapat dikembangkan dengan baik. Untuk itulah pemekaran wilayah merupakan solusi yang dapat dilakukan untuk dapat memberikan pelayanan yang lebih baik kepada masyarakat oleh pemerintah daerah.

Sejalan dengan tujuan tujuan awal pembentukan kabupaten Lombok Utara di atas, (Simangunsong, 2016a) menghasilkan bahwa Pemekaran kecamatan harus menjamin adanya peningkatan pelayanan publik, demokratisasi dan kesejahteraan masyarakat baik pada calon kecamatan yang akan dibentuk maupun kecamatan induk. Dalam penelitiannya yang lain, (Simangunsong, 2015) bahwa peningkatan status wilayah administrasi pemerintahan dapat meningkatkan pelayanan civil dan jasa publik melalui pelaksanaan dan penerapan dimensi penyelenggaraan pemerintahan di Kabupaten Administrasi Kepulauan Seribu.

(Simangunsong, 2016) yang meneliti tentang pemekaran Kecamatan di Kabupaten Anambas Kepulauan Riau yang menghasilkaan bahwa: 1). Pembentukan kecamatan tidak boleh mengakibatkan wilayah tertentu dari keccamatan baru menjadi lemah atau tidak mampu menjalankan kegiatan, layanan dan pembangunan pemerintah; 2). Perbedaan antara kemampuan kandidat untuk dibentuk kecamatan dan kecamatan utama tidak boleh memiliki kesenjangan yang tajam; 3). Keseimbangan kemampuan nyata dan potensi kabupaten yang akan terbentuk dan kecamatan utama harus relatif stabil; 4). Perluasan kecamatan harus memastikan bahwa ada peningkatan pelayanan publik, demokratisasi dan kesejahteraan masyarakat, keduanya akan terbentuk kecamatan dan kecamatan utama.

Jauhnya rentang kendali dengan pemerintah induk, Wilayah Pembangunan Utara Kabupaten Lombok Barat yang terdiri dari 5 (lima) kecamatan yaitu Pemenang, Tanjung, Gangga, Kayangan dan Bayan melahirkan aspirasi masyarakat untuk membentuk kabupaten sendiri dengan tujuan diantaranya untuk mempermudah pelayanan kepada masyarakat, mengembangkan potensi daerah serta dapat meningkatkan partisipasi masyarakat dalam pembangunan. Kemudian cita-cita tersebut terwujud menjadi daerah otonom baru (DOB) pada 21 Juli 2008 berdasarkan Undang-undang Nomor 26 Tahun 2008 tentang Pembentukan Kabupaten Lombok Utara di Provinsi Nusa Tenggara Barat.

Permasalahan yang diangkat dalam penelitian ini dirumuskan yaitu bagaimana dampak pemekaran daerah terhadap kinerja ekonomi dan pelayanan publik di Kabupaten Lombok Utara?.

\section{METODE}

Penelitian ini menggunakan pendekatan kuantitatif merupakan penelitian yang berlandaskan pada filsafat positivisme, digunakan untuk meneliti pada populasi atau sampel tertentu dengan tujuan untuk menguji hipotesis yang telah ditetapkan.

Variabel-variabel yang digunakan dalam penelitian ini adalah Produk Domestik Regional Bruto (PDRB), PDRB 


\section{Jurnal Ilmu Pemerintahan: Kajian Ilmu Pemerintahan dan Politik Daerah, Vol 3 (1), April 2018 - 19 \\ Raden Hady Santika, Budi Santoso, Hadi Mahmudi}

Perkapita, Pemerataan Ekonomi, Kesehatan, Pendidikan dan Infrastruktur.

a. PDRB merupakan jumlah produksi barang dan jasa yang dihasilkan oleh suatu daerah pada tahun tertentu.

b. PDRB Perkapita, merupakan PDRB dibagi jumlah penduduk yang ada disuatu daerah.

c. Kesehatan, yaitu jumlah tenaga kesehatan dan sarana kesehatan yang tersedia.

d. Pendidikan, yaitu menghitung pertumbuhan jumlah siswa, guru dan fasilitas sekolah serta rasio siswa dengan guru di Kabupaten Lombok Utara.

e. Infrastruktur, yaitu menghitung pertumbuhan infrastruktur berupa jalan raya, jumlah pelanggan PDAM dan Listrik di Kabupaten Lombok Utara.

f. Pemerataan Ekonomi dalam penelitian ini adalah mengukur tingkat kesenjangan ekonomi antar wilayah/kecamatan di Kabupaten Lombok Utara.

Menurut (Fattah, 2013) untuk menghitung pemerataan pembangunan antar wilayah digunakan Indeks Williamson yaitu suatu indeks yang mengukur variasi PDRB perkapita antar daerah. Angka indeks ini berkisar antara $0-1$, dimana jika nilai IW mendekati 1 maka ketimpangannya semakin tinggi dan sebaliknya apabila angka IW semakin kecil dan mendekati 0 maka hasil pembangunannya sangat merata di semua daerah/wilayah.

Hipotesis dalam penelitian ini adalah: 1). Diduga kinerja ekonomi dan pelayanan publik di Kabupaten Lombok Utara lebih baik dibandingkan sebelum dilakukannya pemekaran. 2). Diduga pemerataan ekonomi Kabupaten Lombok Utara lebih baik dibandingkan sebelum dilakukannya pemekaran.

Untuk menganalisis perbedaan kinerja daerah kabupaten Lombok Utara sebelum dan setelah pemekaran digunakan Uji Hipotesis Beda Dua Rata-rata pada setiap indikator kinerja dan pemerataan ekonomi tersebut di atas. Rumusan hipotesis dalam penelitian ini diuji menggunakan rumus sebagai berikut (Mariani, 2013):

Ho $: \mu 1=\mu 1$

На $: \mu 1 \neq \mu 2$

dimana:

$\mu 1=$ Rata-rata sebelum pemekaran

$\mu 2=$ Rata-rata setelah pemekaran

thitung $=\frac{\bar{d}}{S e}$

$S e=\frac{S d}{\sqrt{n}}$

$\bar{d}=\frac{\sum d}{n}$

$\mathrm{Sd}=\sqrt{\frac{\sum d^{2}-\frac{\left(\sum d\right)^{2}}{n}}{n-1}}$

Kriteria pengujiannya adalah:

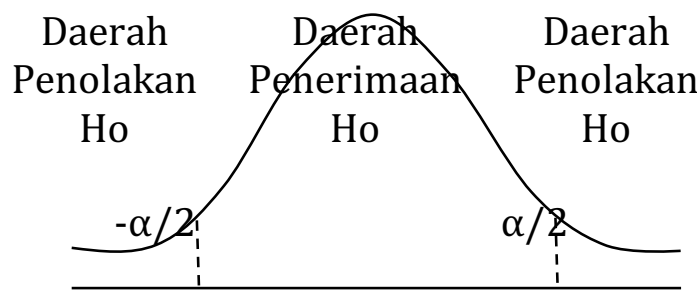

Selanjutnya dilakukan uji statistik dengan membandingkan nilai $t$ hitung 


\section{Jurnal Ilmu Pemerintahan: Kajian Ilmu Pemerintahan dan Politik Daerah, \\ Vol 3 (1), April 2018 - 20 \\ Raden Hady Santika, Budi Santoso, Hadi Mahmudi}

dengan $\mathrm{t}$ table pada taraf kepercayaan 95 persen dan $\alpha$ (alpha) sebesar 5 persen. Kriteria pengambilan keputusan adalah sebagai berikut:

a. Jika - $\mathrm{t}$ tabel $(\alpha / 2) \leq-\mathrm{t}$ hitung atau $\mathrm{t}$ hitung $\leq \mathrm{t}$ tabel $(\alpha / 2)$, maka terima Ho dan tolak $\mathrm{Ha}$, artinya rata-rata indikator kinerja ekonomi sebelum pemekaran wilayah sama dengan setelah pemekaran wilayah. Hal ini berarti Kabupaten Lombok Utara belum berhasil meningkatkan indikator kinerja dan pemerataan ekonomi yang diteliti.

b. Jika - $t$ hitung $<-\mathrm{t}$ tabel $(\alpha / 2)$ atau $\mathrm{t}$ hitung $>\mathrm{t}$ tabel $(\alpha / 2)$, maka terima Ha dan tolak Ho, artinya rata-rata indikator kinerja ekonomi sebelum pemekaran wilayah tidak sama atau berbeda dengan setelah pemekaran wilayah. Hal ini berarti Kabupaten Lombok Utara telah berhasil meningkatkan indikator kinerja dan pemerataan ekonomi yang diteliti.

\section{HASIL DAN PEMBAHASAN}

\section{Hasil Penelitian}

Hasil penelitian berupa data PDRB, PDRB perkapita, Jumlah Tenaga Kesehatan, Jumlah Fasilitas Kesehatan, Jumlah Siswa, Jumah Guru, Jumlah Fasilitas Pendidikan, Jumlah Pelanggan PDAM, Pelanggan Listrik dan Panjang Jalan. Data sebelum pemekaran yaitu tahun 2000 sampai tahun 2007 dan setelah pemekaran menggunakan data 2008 - 2016.

PDRB Kabupaten Lombok Utara dapat dilihat pada Tabel 1 berikut.

Tabel 1. PDRB Kabupaten Lombok Utara

\begin{tabular}{cccc}
\hline \hline Tahun & $\begin{array}{c}\text { Sebelum } \\
\text { Pemekaran }\end{array}$ & Tahun & $\begin{array}{c}\text { Setelah } \\
\text { Pemekaran }\end{array}$ \\
\hline 2000 & 161.329 .428 & 2009 & 620.559 .177 \\
2001 & 168.088 .093 & 2010 & 646.867 .427 \\
2002 & 175.781 .468 & 2011 & 684.442 .310 \\
2003 & 490.765 .940 & 2012 & 712.737 .510 \\
2004 & 515.546 .944 & 2013 & 2.704 .664 .800
\end{tabular}

\begin{tabular}{cccc}
\hline \hline Tahun & $\begin{array}{c}\text { Sebelum } \\
\text { Pemekaran }\end{array}$ & Tahun & $\begin{array}{c}\text { Setelah } \\
\text { Pemekaran }\end{array}$ \\
\hline 2005 & 536.785 .485 & 2014 & 2.828 .842 .100 \\
2006 & 560.201 .044 & 2015 & 2.962 .781 .300 \\
2007 & 585.304 .419 & 2016 & 3.110 .766 .500 \\
\hline \hline
\end{tabular}

Pada tabel 1, menunjukkan bahwa pola pertumbuhan PDRB Kabupaten Lombok Utara sebelum pemekaran sebesar 4,46\%. Setelah pemekaran daerah Kabupaten Lombok Utara mengalami peningkatan sebesar 4,75 \%.

\section{Analisis Data ( t-test)}

Analisis data menggunakan metode index williamson, mengukur variasi PDRB perkapita antar daerah. Angka indeks ini berkisar antara $0-1$, dimana jika nilai IW mendekati 1 maka ketimpangannya semakin tinggi dan sebaliknya apabila angka IW semakin kecil dan mendekati 0 maka hasil pembangunannya sangat merata di semua daerah / wilayah.

Analisis data disajikan pada tabel 2, hasil $\mathrm{t}$ test (uji dua sisi) untuk membuktikan rata-rata sebelum dan setelah pemekaran.

Menurut UNDP (2008) terdapat indikator penilaian Daerah Pemekaran Baru, indikator tersebut dapat dilihat pada Tabel 2 yang menunjukkan bahwa nilai $\boldsymbol{t}$ test pada semua indikator penilaian lebih besar dari t-tabel sehinga terdapat peningkatan indikator perekonomian yang dihasilkan setelah pemekaran daerah.

\section{Pembahasan}

\section{Pertumbuhan Ekonomi}

Pertumbuhan ekonomi adalah kenaikan kapasitas dalam jangka panjang dari Negara yang bersangkutan untuk menyediakan berbagai barang ekonomi kepada penduduknya. 


\section{Jurnal Ilmu Pemerintahan: Kajian Ilmu Pemerintahan dan Politik Daerah, \\ Vol 3 (1), April 2018 - 21}

Raden Hady Santika, Budi Santoso, Hadi Mahmudi

Tabel 2. Hasil Perhitungan T-test: Paired Two Sample for Means

\begin{tabular}{|l|r|r|r|r|r|r|}
\hline \multicolumn{1}{|c|}{ Indikator Penilaian } & t-test & t-tabel & Prob. & $\begin{array}{c}\boldsymbol{\alpha}(\mathbf{5} \\
\text { persen) }\end{array}$ & \multicolumn{1}{c|}{$\begin{array}{c}\text { Mean } \\
\text { sebelum } \\
\text { pemekaran }\end{array}$} & \multicolumn{1}{c|}{$\begin{array}{c}\text { Mean } \\
\text { setelah } \\
\text { pemekaran }\end{array}$} \\
\hline Pertumbuhan Ekonomi & 3,758 & 2,365 & 0,007 & 0,05 & 399225352,6 & 1783957641 \\
\hline PDRB Perkapita & 3,739 & 2,365 & 0,007 & 0,05 & 2085,84 & 8544,24 \\
\hline Jumlah Siswa & 22,118 & 2,365 & 9,759 & 0,05 & 32353,50 & 38517,25 \\
\hline Jumlah Guru & 3,825 & 2,365 & 0,006 & 0,05 & 1714 & 2328,625 \\
\hline Fasilitas Pendidikan & 4,627 & 2,365 & 0,002 & 0,05 & 241,5 & 337,625 \\
\hline Jlh. Tenaga Kesehatan & 5,851 & 2,365 & 0,001 & 0,05 & 79,13 & 304,38 \\
\hline Fasilitas Kesehatan & 4,660 & 2,365 & 0,002 & 0,05 & 28,13 & 32,63 \\
\hline Panjang Jalan & 3,150 & 2,365 & 0,016 & 0,05 & 776,5 & 872,4375 \\
\hline Pelanggan PDAM & 9,099 & 2,365 & 3,969 & 0,05 & 4667,125 & 8716,125 \\
\hline Pelanggan PLN & 9,112 & 2,365 & 3,935 & 0,05 & 26451,75 & 44433,25 \\
\hline Pemerataan Ekonomi & 4,930 & 2,365 & 0,002 & 0,05 & 0,1425 & 0,09 \\
\hline
\end{tabular}

Kemampuan negara dalam menyediakan barang ekonomi kepada penduduknya tercermin pada angka PDRB negara tersebut (Todaro, 1998). Hal tersebut ditunjukkan oleh laju pertumbuhan ekonomi sebelum pemekaran rata-rata sebesar 4,75\% dan rata-rata setelah pemekaran meningkat menjadi 5,81\%.

Hasil penelitian ini sejalan dengan penelitian yang dilakukan oleh (Adi, 2012) bahwa alasan pemekaran daerah diantaranya adalah untuk mempercepat pembangunan ekonomi daerah melalui pemanfaatan potensi local yang selama ini belum dikelola dengan baik oleh daerah induk. Pertumbuhan ekonomi Kabupaten Lombok Utara salah satunya didorong oleh kebijakan Pemerintah Daerah dalam memberikan bantuan usaha ekonomi produktif dalam bentuk Pemberian Modal Kerja kepada Wira Usaha Baru (WUB) serta pemberian bantuan peralatan usaha baik dalam bentuk kelompok maupun perorangan.

\section{PDRP Perkapita}

Hasil t-test menunjukkan bahwa PDRB Perkapita Kabupaten Lombok
Utara mengalami peningkatan yang signifikan pasca pemekaran daerah dengan $P$ value yaitu 0,007 lebih rendah dari nilai alpha sebesar 0,05. Dengan menerima hipotesis alternatif (Ha) dapat disimpulkan bahwa PDRB Perkapita Lombok Utara lebih tinggi meningkat setelah terjadinya pemekaran.

Sebelum pemekaran rata-rata PDRB perkapita (dalam ribuan) sebesar 2.086.000 rupiah dan setelah pemekaran meningkat menjadi 14.509.650 rupiah.

Peningkatan PDRB di Kabupaten Lombok Utara diimbangi oleh pemerataan perekonomian masyarakat. Hal tersebut dibuktikan oleh nilai Indeks Williamson sebagai tolok ukur tingkat kesenjangan ekonomi antar daerah menunjukkan bahwa sebelum pemekaran nilai indeks sebesar 0,14 menurun setelah pemekaran dengan nilai indeks 0,09. Sehingga kesenjangan perekonomian semakin rendah setelah pemekaran Daerah.

\section{Pertumbuhan Pembangunan}

Pembangunan merupakan hal wajib yang dilakukan oleh pemerintah daerah dengan cara perencanaan. 


\section{Jurnal Ilmu Pemerintahan: Kajian Ilmu Pemerintahan dan Politik Daerah, \\ Vol 3 (1), April 2018 - 22 \\ Raden Hady Santika, Budi Santoso, Hadi Mahmudi}

Pembangunan di Kabupaten Lombok Utara dapat dilihat pada grafik berikut ini.

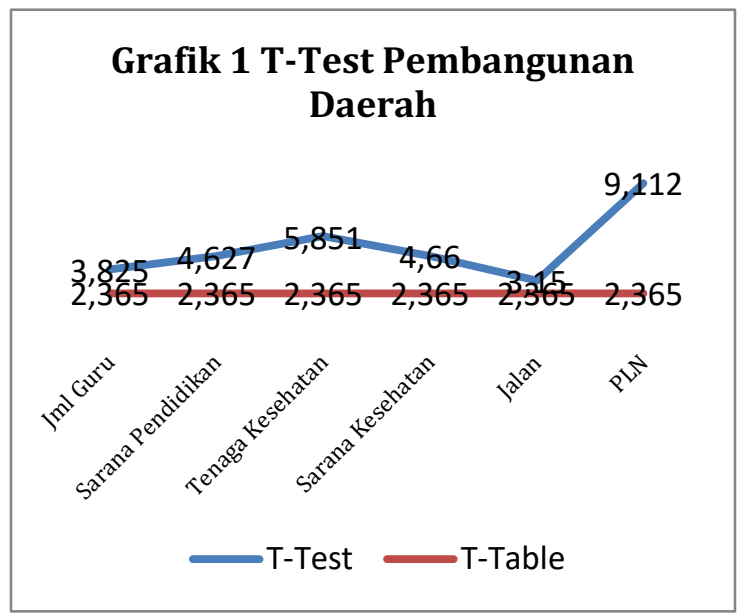

Pembangunan yang dilakukan oleh pemerintahan Kabupaten Lombok Utara seperti pemenuhan kebutuhan guru, sarana pendidikan, tenaga kesehatan, sarana kesehatan, jalan dan penerangan. Setelah pemekaran Daerah, pemerintah mampu memenuhi kebutuhan dasar masyarakatnya. Terlihat pada nilai $\boldsymbol{t}$-test yang dihasilkan diatas nilai t-table.

\section{SIMPULAN DAN SARAN}

\section{Simpulan}

Hasil penelitian dampak pemekaran daerah di Kabupaten Lombok Utara dengan membandingkan pertumbuhan perekonomian, pemerataan ekonomi, dan pembangunan daerah sebelum dan setelah pemekaran daerah pada tahun 2017. Bahwa pemekaran daerah merupakan solusi terbaik untuk pemerataan pembangunan daerah dengan mengutamakan kesejahteraan masyarakat.

\section{Saran}

Setelah melakukan kajian dampak pemekaran daerah di Kabupaten Lombok
Utara, terdapat rekomendasi yang dilakukan oleh pemerintah, yakni:

- Optimalisasi pembangunan melalui optimalisasi layanan pariwisata sebagai sumber Pendapatan Asli Daerah (PAD)

- Transportasi yang terintegrasi sehingga pemenuhan kebutuhan dasar masyarakat tercukupi dengan cepat.

- Untuk penelitian lebih lanjut bahwa dapat dikaji kembali mengenai indeks kepuasan masyarakat terhadap pelayanan yang diberikan oleh pemerintah setelah pemekaran daerah baru.

\section{DAFTAR PUSTAKA}

Adi, P. (2012). Kemampuan Keuangan Daerah dalam Era Otonomi dan Relevansinya dengan Pertumbuhan Ekonomi (Studi pada Kabupaten dan Kota Se Jawa-Bali). Retrieved from http://repository.uksw.edu/handle/12 3456789/1318

Fattah, A. R. (2013). Analysis of Regional Economic Development in the Regency/Municipality at South Sulawesi Province In Indonesia. Journal of Economics. Retrieved from http://www.academia.edu/download/ 30632997/Analysis_of_Regional_Econo mic_Development_in_the_Regency.pdf

Harmantyo, D. (2007). PEMEKARAN DAERAH DAN KONFLIK KERUANGAN Kebijakan Otonomi Daerah dan Implementasinya di Indonesia. Makara Sains, 11(1), 16-22.

Harmantyo, D. (2011). Desentralisasi, otonomi, pemekaran daerah dan pola perkembangan wilayah di Indonesia. Geografi.Ui.Ac.Id. Retrieved from http://geografi.ui.ac.id/portal/wpcontent/uploads/2012/03/harmantyo 1.doc

Hilman, Y. A. (2017). Kelembagaan Kebijakan Pariwisata di level Desa. Jurnal Ilmu Pemerintahan: Kajian Ilmu Pemerintahan Dan Politik Daerah, 2(2), 


\section{Jurnal Ilmu Pemerintahan: Kajian Ilmu Pemerintahan dan Politik Daerah, Vol 3 (1), April 2018 - 23 \\ Raden Hady Santika, Budi Santoso, Hadi Mahmudi}

150.

https://doi.org/10.24905/jip.v2i2.711

Jhingan, M. (1985). The economics of development and planning (with special reference to India). Retrieved from http://agris.fao.org/agrissearch/search.do?recordID=XF201504 6756

Mariani, L. (2013). Analisis Kinerja Keuangan Pemerintah Sesudah Pemekaran Daerah. Jurnal Akuntansi, 1(2). Retrieved from http://ejournal.unp.ac.id/students/ind ex.php/akt/article/view/641

Rustiadi, E., Saefulhakim, S., \& Panuju, D. (2009). Perencanaan dan pengembangan wilayah. Retrieved from https://www.google.com/books?hl=id \&lr=\&id=vW6rDAAAQBAJ\&oi=fnd\&pg= PT1\&dq=sistem+perencanaan+pemban gunan+nasional\&ots=Z3SaWuq_gY\&sig =A-18bhuwUMEqlRMwwaLvGIFH_sU

Simangunsong, F. (2015). KAJIAN PENGGALIAN POTENSI DAN PENINGKATAN PENDAPATAN ASLI DESA DI KABUPATEN SEKADAU PROVINSI KALIMANTAN BARAT. Jurnal Administrasi Publik: Public Administration Journal, 5(1), 38-49. Retrieved from http://ojs.uma.ac.id/index.php/adminp ublik/article/view/1069

Simangunsong, F. (2016a). Kajian Desain Penataan Daerah Bidang Manajemen Pemerintahan Di Provinsi Papua Barat. Jurnal Ilmu Pemerintahan : Kajian Ilmu Pemerintahan Dan Politik Daerah, 1(1), 49.

https://doi.org/10.24905/jip.v1i1.434

Simangunsong, F. (2016b). Kajian Desain Penataan Daerah Bidang Manajemen Pemerintahan Di Provinsi Papua Barat. Jurnal Ilmu Pemerintahan: Kajian Ilmu Pemerintahan Dan Politik Daerah, 1(1), 49. https://doi.org/10.24905/jip.v1i1.434

Simangunsong, F., \& Simangunsong, F. (2016). Kajian Desain Penataan Daerah Bidang Manajemen Pemerintahan Di Provinsi Papua Barat. Jurnal Ilmu Pemerintahan: Kajian Ilmu Pemerintahan Dan Politik Daerah, 1(1). https://doi.org/http://dx.doi.org/10.2 4905/jip.v1i1.434

Sudiar, S. (2017). Kebijakan Pembangunan Perbatasan dan Kesejahteraan Masyarakat di Wilayah Perbatasan Pulau Sebatik, Indonesia. $E$ Journals.Unmul.Ac.Id, 1(3), 389-400. Retrieved from http://ejournals.unmul.ac.id/index.php/JParadi gma/article/view/316

UNDP, B. N.-J., \& 2008, undefined. (n.d.). Studi Evaluasi Dampak Pemekaran Daerah. Academia.Edu. Retrieved from http://www.academia.edu/download/ 35118317/pemekaran_ID.pdf

Zainudin, A. (2016). Model Kelembagaan Pemerintahan Desa. Jurnal IImu Pemerintahan: Kajian Ilmu Pemerintahan Dan Politik Daerah, 1(2), 332.

https://doi.org/10.24905/jip.v1i2.607

\section{PROFIL SINGKAT}

Penulis adalah Raden Hady Santika, lahir di Lombok Barat, 22 Februai 1980. Merupakan peneliti program pascasarjana Magister Ekonomi Universitas Mataram. Selain itu bekerja sebagai ASN di Kecamatan Tanjung Kabupaten Lombok Utara Provinsi Nusa Tenggara Barat. Tempat tinggal di Jalan Saleh Sungkar, Kelurahan Ampenan Utara, Kecamatan Ampenan, Kota Mataram, Provinsi Nusa Tenggara Barat. 